\title{
Review Section
}

\section{Black Veganism and the Animality Politic}

Aph Ko and Syl Ko, Aphro-ism: Essays on Pop Culture, Feminism, and Black Veganism from Two Sisters. Lantern Books, 2017. 202 pp.

I was first introduced to Aph and Syl Ko when they reached out to me in early 2013 , just in the infancy of our blogging careers. It was an exciting time for digital activism, as feminist online publishing seemed to bridge the gap between the forgotten tomes of vegan feminist theory collecting dust in libraries and the vibrant, fast-paced conversations happening across social media. In July of that year, I launched Vegan Feminist Network (VFN) in heavy collaboration with Aph. It is a blog intended to bring voice to critical ideas about intersectionality and social justice within the nonhuman animal rights movement, ideas that had been stifled in prevailing theoretical dialogues and activist conversations. Aph and Syl contributed a number of essays to VFN, all of which were immensely popular. Their perspective was so fresh and thought-provoking, it seemed real change was possible. Cracks were beginning to emerge in the white patriarchal hegemony that had reified American nonhuman animal rights efforts, and this included my own positionality. I was personally changed as an activist and a thinker in an immeasurable way through my early working relationship with them, and I know many other activists and scholars can report having experienced the same Ko effect.

Aph and Syl soon moved on from vFn to launch and curate spaces of their own, and rightfully so, as great minds such as theirs need freedom and control to most appropriately disseminate their ideas. The two were (and are) active in a number of blogs, and Aphro-ism (2017) constitutes a collection of essays from these projects, mostly composed in 2015 and 2016. This editorial choice has its advantages and disadvantages. By focusing on pop culture and internet politics, the topics addressed are timely, relevant, and interesting to non-academics. 
However, this approach also inhibits the longevity of the arguments, as the examples provided as launching points into the deeper theoretical analyses grow quickly stale given the rapidity of cultural change and the fluidity of online trending. The YouTube videos and blog references that are fundamental to most essays, for instance, have already become dated and lost to memory. In this way, Aphro-ism is rather similar to the highly popular work Bad Feminist by Roxane Gay (2014). Like Aphro-ism, Bad Feminist is collection of loosely related (and sometimes unrelated) essays on race, class, and feminism that engagingly applies difficult academic ideas to hot topics. It is feminism for the real world. Yet, also like Aphro-ism, its heavy reliance on cultural references immediately dates the analysis and will likely confound readers who are not immersed in social media as well as those, immersed or not, who pick up the book some years from now.

That said, future readers will be duly rewarded in sifting through past descriptions of forgotten viral videos to discover the critical theory within. Perhaps the most enduring argument presented relates to the political nature of animality. Although fitting soundly within the larger, established discipline of post-humanism, Aphro-ism does not engage at all with this literature, and this is likely to the benefit of the reader, as post-humanist discourse is exceedingly obtuse and frequently boring. Instead, the Ko sisters apply zoth century critical race scholarship (Anzaldúa, Fanon, hooks, Wynter, etc.) and 21st century contributions by bloggers and activists to make sense of the animal question. Most fundamentally, they critique popular applications of intersectionality theory, identifying that what has traditionally been defined as "human" has always been categorized as white, male, and European, while racial and ethnic minorities, women, and other marginalized groups have been dualistically constructed as "animal." Thus, "animal" is not so much a catch-all category meant to refer to nonhuman species, but to all manner of disenfranchised groups, humans included. Animality is, they insist, endemic to the colonialist project, providing justification for social control and suppression.

The Kos argue that anti-racism activists, feminists, and vegans all have a stake in challenging the false divide between human and animal, and, more specifically, challenging the category of "animal" itself. Without challenging this basic mechanism of oppression, activists are bound to fail in their efforts for liberation. In fact, they merely embrace the same oppressive logic by either ignoring (or rejecting) the relevance of animality or insisting that intersectionality praxis stop short of species solidarity. Doing so dangerously preserves hierarchies. As Aph warns: "What hasn't occurred to many of us is that this model of compartmentalizing oppressions tracks the problematic Eurocentric compartmentalization of the world and its members in general" 
(p. 71). From the same reasoning, vegans who do not incorporate a critical racial lens are missing the entire point of speciesism: marking particular bodies as distinct from the dominant group based on perceived physical, cognitive, and cultural differences, and then employing this distinction to rationalize oppressive treatment. Racism and speciesism are inherently entangled. Explains Syl: "... the organizing principle for racial logic lies in the human-animal divide, wherein the human and the animal are understood to be moral opposites" (p. 66). The Kos are careful not to prescribe a "we are all animals" perspective to solve this boundary-maintenance issue, as this is poised to deprecate rather than accommodate difference. There is little need to push for sameness, and such a push usually maintains the dominant group as the standard to which others should aspire.

Unfortunately, in advancing the importance of acknowledging and ultimately deconstructing animality, nonhuman animals become absent referents in the Kos' analysis. Readers are introduced to nonhumans primarily as metaphors and not living, breathing, suffering beings themselves. There is an intentionality to this omission in the authors' justification: “... veganism just can't be all about the animals.... We're the ones who talk about and act on this problem. So, it will always have to be a little bit about us, too" (p. 55). Indeed, race (and other identities) shape the vegan praxis of whites as well, but their status within the dominant group renders this bias invisible in the mainstream movement. The Kos, in any case, are not especially interested in addressing the nonhuman experience, emphasizing instead that there are many perspectives and approaches to veganism, and not all of them must necessarily center nonhuman animals. They insist that there need not be one dominant, allencompassing Veganism. Rather, ethical veganism is a patchwork of diverse positions and outlooks. That some activists prioritize animality politics as a means for tackling race relations does not mean that they also reject or have plans to supersede the anti-speciesist approach. It is not a zero-sum game.

Although this is certainly a contentious claim in conventional, anti-speciesist circles, it isn't entirely clear that the nonhuman animal rights movement is the intended audience of Aphro-ism. Actually, the intended audience for Aphro-ism is multi-faceted. Because it is a collection of essays, each piece is likely to appeal to different groups, including Black vegans, other vegans of color, white vegans, nonvegan Blacks, and white folks in general. Really, it is a narrative trumpeting from the margins, building the case for the fruitfulness of marginality. The aim of Black veganism as advanced in Aphro-ism is not to tokenize people of color for white vegan, post-racial fantasies, nor is it to improve the "respectability" of people of color whom white anti-speciesists frequently depict as having gone from the ghetto to gentrified by the magic 
of plants. Black veganism is a political protest against the oppressiveness of animality, Eurocentric hierarchy-building, and harmful foodways. Rather than advocate a recentering of Black veganism, the Kos insist that the very notion of maintaining a center (i.e., a dominant cultural identity) is problematic in of itself and supports hierarchical thinking.

The authors are explicit in their disinterest in expending energy on "... serving as intellectual maids to white people ..." (p. 10), but it is clear that the white vegans who currently control the trajectory and discourse of the mainstream nonhuman animal rights movement in the West are well-positioned to benefit from this book. The Kos are adamant that it should not be people of color who are burdened with teaching and guiding whites because it so greatly distracts from futurist work. However, it is a message that still needs to be heard, and I am somewhat disappointed that Aphro-ism is not designed to at least be approachable to the uninitiated from dominant groups. Stylistically, it is highly philosophical, such that the reader is presumed to be already well-learned in critical race theory, and its multi-faceted focus (in addition to animality, essays examine such topics as the Black Lives Matter movement, respectability politics, and the role of social media in sustaining the notoriously elusive American dream) suggests to me that many white vegans would find the arguments difficult to understand without some background. This is fine; this book was not written to teach white vegans. Perhaps that is a book that still needs to be written, and this is work that must be undertaken by whites themselves. The key thesis of Aphro-ism is that too much time has already been squandered fighting for inclusion in white spaces and pandering to white ignorance and emotional needs. Now is the time for building supportive and inclusive spaces for the traditionally marginalized; now is also the time for building bridges to like-minded social justice movements lacking the all-important analysis of animality.

While Aphro-ism offers an intriguing snapshot into Black vegan feminism as it pertains to the here and now, it leaves me hungry for a more enduring work that can sustain the shifty temperament of pop culture. Likewise, by retaining the blog format, Aphro-ism is limited in its ability to engage with theory to the depth necessary for unpacking the Kos' ideas. To be clear, both Ko sisters are ample, trained theorists, and leading critical race scholars are referenced scrupulously to contextualize their arguments. Yet, the piecemeal nature of blog writing necessarily means that academic nuance and deeper explanation of core concepts will be shortchanged. I am not sure that this is exactly what the audience (who are presumably activists, not academics) needs, but the bounty of the Kos' analysis seems to deserve a full-length book. This is particularly so as no other work to date has accomplished this. For instance, Breeze Harper's 
(2010) Sistah Vegan, while equally groundbreaking, is also a collected work, and the ecofeminist tradition only touches on race incidentally, rarely offering more than a chapter or two on race and animality. It is my hope that Aphro-ism excites the vegan discourse and evolves into future contributions. Social movements across the left would benefit tremendously.

\author{
Corey Lee Wrenn \\ University of Kent in Canterbury, UK \\ Corey.wrenn@gmail.com
}

\title{
References
}

Breeze Harper, A. (2010). Sistah vegan: Black female vegans speak on food, identity, health, and society. Brooklyn: Lantern Books.

Gay, R. (2014). Bad feminist: Essays. New York: HarperCollins. 